\section{$16^{\circ}$ \\ ERGODESIGN \\ USIHC \\ CINAHPA}

$16^{\circ}$ USIHC - Congresso Internacional de Ergonomia e Usabilidade de Interfaces Humano Computador

CINAHPA | 2017 - Congresso Internacional de Ambientes Hipermídia para Aprendizagem.

\title{
MOODLE COMO AMBIENTE VIRTUAL DE APOIO A MEDIAÇÃO PEDAGÓGICA: FRAGILIDADES PERCEBIDAS PELO USUÁRIO
}

\author{
MOODLE AS A VIRTUAL ENVIRONMENT TO SUPPORT THE \\ PEDAGOGICAL MEDIATION: USER-PERCEIVED FRAGILITIES
}

\author{
Giovana Schuelter ${ }^{1}$, Dra. \\ Sabrina Bleicher², Dra. \\ Carlos de $\mathrm{Mello}^{3}$, Msc.
}

\author{
(1) Instituto Federal de Santa Catarina \\ e-mail: giovana.schuelter@ifsc.edu.br \\ (2) Instituto Federal de Santa Catarina \\ e-mail: sabrina.bleicher@ifsc.edu.br \\ (3) Instituto Federal de Santa Catarina \\ e-mail: carlos.mello@ifsc.edu.br
}

Ambiente Virtual de Ensino e Aprendizagem, Moodle, Fragilidades

\begin{abstract}
Inúmeras são as possibilidades para o desenvolvimento de processos educativos amparados pelas tecnologias, na modalidade a distância ou no ensino presencial. O diferencial está na qualidade da mediação do processo educativo, onde os envolvidos necessitam de plataformas de aprendizagem que possibilitem interação, compartilhamento e colaboração de qualidade. Nesta perspectiva, este artigo apresenta uma avaliação das fragilidades apresentadas pela plataforma Moodle quando utilizada como ambiente virtual de apoio a mediação pedagógica. A avaliação foi realizada por estudantes da Pós-graduação em Formação Pedagógica para Docência na Educação Profissional e Tecnológica do Instituto Federal de Santa Catarina (IFSC), curso ofertado integralmente a distância. Assim sendo, este trabalho apresenta assuntos focados na mediação pedagógica de ambientes virtuais de ensino aprendizagem e, em seguida, apresenta a avaliação realizada: sua metodologia, os resultados obtidos e as considerações finais. Espera-se, com esta publicação, contribuir com as pesquisas da área.
\end{abstract}

\section{Virtual Environment of Teaching and Learning, Moodle, Fragilities}

There are countless possibilities for the development of educational processes supported by technologies, in the distance modality or in face-to-face teaching. The difference lies in the quality of the mediation of the educational process, where those involved need learning platforms that allows quality interaction, sharing and collaboration. In this perspective, this article presents an evaluation of the fragilities presented by the Moodle platform when used as a virtual environment to support pedagogical mediation. The evaluation was carried out by students of the Postgraduate Course in Pedagogical Training for Teaching in Professional and Technological Education of the 
$16^{\circ}$ USIHC - Congresso Internacional de Ergonomia e Usabilidade de Interfaces Humano Computador

CINAHPA | 2017 - Congresso Internacional de Ambientes Hipermídia para Aprendizagem.

Federal Institute of Santa Catarina (IFSC), a distance education course. Therefore, this paper presents subjects focused on the pedagogical mediation of virtual learning environments and also presents the evaluation: its methodology, the results obtained and the final considerations. It is hoped, with this publication, to contribute with the researches of the area.

\section{Introdução}

Vivenciamos a era de novas possibilidades, do desenvolvimento de tarefas com o uso das tecnologias e este cenário demanda a oferta de espaços construtivos e colaborativos. Na mesma linha, a área educacional vem se beneficiando com riqueza de novas ferramentas.

Segundo Marcon e Goedert (2015, p. 41), "as tecnologias encontram-se em constante transformação, não somente em relação ao hardware, mas também na concepção de conectividade e mobilidade, caracterizando a revolução tecnológica e a nova cultura digital". Essas questões implicam diferentes transformações nos processos educativos escolares.

O desafio atualmente está focado em dois pontos cruciais: o primeiro deles é a disponibilização de sistemas que auxiliem o processo de ensino de aprendizagem. O segundo, consequência do primeiro, é conseguir ambientes virtuais de ensino, robustos e de qualidade que possam disponibilizar ferramentas interativas e de entrega de conhecimento, favorecendo o processo educativo.

Neste contexto, apresenta-se a temática deste artigo: os Ambientes Virtuais de Ensino e Aprendizagem (AVEAs), amplamente utilizados por instituições de ensino seja como espaços para o estudo na modalidade a distância ou servindo de apoio aos estudos presenciais.

Ao buscar pesquisas sobre os tipos de AVEAs, é possível encontrar diversas plataformas distintas, algumas desenvolvidas particularmente por empresas, com alto custo de investimento e outras plataformas de livre acesso. Dentro do cenário existente, atualmente a plataforma de aprendizagem mais utilizada mundialmente é o Moodle - Modular Object-Oriented Dynamic Learning Environment, empregada para os mais diversos tipos de cursos ou atividades educativas, conforme cita o portal educação: "A plataforma Moodle vem sendo utilizada para vários tipos de atividades. Inclusive instituições de ensino tanto do básico como também do superior e centros de formação. Várias instituições que envolvem formação de grupos de estudo, treinamento de professores e até desenvolvimento de projetos. (PORTAL EDUCAÇÃO, 2013, p.1)".

Diante da situação exposta inicialmente, neste artigo desenvolve-se um estudo que foca, inicialmente, na educação utilizando Ambientes Virtuais de Ensino e Aprendizagem, levando em conta a importância da mediação. Na sequência se apresenta uma pesquisa sobre a Plataforma Moodle e sua contribuição para o processo educativo e, a seguir, a avaliação realizada.

\section{Fundamentação Teórica}

\section{Importância da mediação}

A mediação e, por consequência, a comunicação, são elementos importantes para a convivência em sociedade. Em um mundo globalizado onde ocorrem infinitas e dinâmicas interações com trocas de informações de diferentes opiniões e objetivos, é fundamental a existência de um processo comunicativo organizado para que os objetivos das interações sejam alcançados.

Na educação, a mediação e a comunicação se fazem presentes como elementos fundamentais no processo educativo, podendo ser vistos como processo de construção de novos conhecimentos. Segundo Gomes (2008, p. 01): "[..] o processo de construção do conhecimento se dá por meio de um movimento complexo, no qual os sujeitos interagem entre si, mas também com as informações, processando-as para a partir de seus enquadramentos e de suas possibilidades cognitivas se apropriarem dos conteúdos acessados". 
$16^{\circ}$ Ergodesign - Congresso Internacional de Ergonomia e Usabilidade de Interfaces Humano Tecnológica: Produto, Informações Ambientes Construídos e Transporte

$16^{\circ}$ USIHC - Congresso Internacional de Ergonomia e Usabilidade de Interfaces Humano Computador

CINAHPA | 2017 - Congresso Internacional de Ambientes Hipermídia para Aprendizagem.
Nessa construção, a mediação tem caráter enriquecedor, já que permite direcionamentos no estudo e no acesso às informações para formar a construção de novos conhecimentos.

O processo comunicativo precisa ser intenso para facilitar e enriquecer o aprendizado. Para Kenski (2008, p.1), "o processo da comunicação humana com finalidades educacionais transcende o uso de equipamentos e se consolida pela necessidade expressa de interlocução, de trocas comunicativas. Vozes, movimentos e sinais corporais são formas ancestrais de manifestações humanas no sentido da comunicação, visando à aprendizagem do outro ser". No contexto da educação a distância, com suas características específicas de distanciamento geográfico, a proposta para a mediação, segundo a mesma autora, baseia-se no uso das Tecnologias de Informação e Comunicação (TICs), que oferecem ferramentas para tornar possível o processo interativo e efetivo na modalidade.

As tecnologias acompanham o crescimento e as mudanças da humanidade com diferentes descobertas e atingem diversas áreas. Na educação, as tecnologias auxiliam e podem promover melhores apresentações de conteúdos e favorecer a comunicação e mediação, mesmo entre pessoas localizadas em diferentes locais do globo terrestre.

Para atender as demandas atuais, as tecnologias de informação e comunicação oferecem uma gama de ferramentas que possibilitam a $\mathrm{EaD}$ uma maior aproximação entre professores, alunos e equipe de acompanhamento de curso. Atualmente podemos contar com os Ambientes Virtuais de Ensino e Aprendizagem, dentro destes sistemas existem ferramentas de entrega de conteúdos e ferramentas de interação, como: fórum, chat, envio de mensagem, entre outras. Esta oferta de tecnologias trouxe para a educação a distância uma nova forma de executar o processo educativo, possibilitou construções conjuntas de aprendizagem, onde os participantes podem interagir diariamente independente do lugar geográfico que se encontram.

O contexto da nova educação mediado pelas tecnologias é reforçado em espaços de discussão, como é o caso do site Brasil Escola, onde o colunista Rodiney Marcelo (2017) cita:"A apropriação das mídias e Tecnologias de Informação e Comunicação (TIC's), no cenário da EAD faz resignificar o conceito de conhecimento. É através das ferramentas tecnológicas, a partir de mediações atuantes que as potencialidades se afloram, o tempo e espaço, já não são mais problemas, proporcionando uma educação sem distância, sem tempo, levando o sistema educacional a assumir um papel, não só de formação de cidadãos pertencentes aquele espaço, mas a um espaço de formação inclusiva em uma sociedade de diferenças" (RODINEY MARCELO, 2017 p.1).

Dentro desta concepção, a mediação pedagógica na modalidade a distância tem sido um assunto amplamente discutido e trabalhado por estudiosos que tratam o tema com a análise de necessidades, como é o caso de Silveira (2014).

É importante ressaltar que a mediação pedagógica deve sempre seguir as estratégias pedagógicas previstas para o curso, para atuar, o professor e a equipe de acompanhamento contam com as ferramentas disponíveis no AVEA. Onde se tem dispositivos como chats, fóruns, blogs, entre outros. Sendo necessário planejar o uso de cada um deles, levando em consideração a proposta pedagógica e as peculiaridades de cada dispositivo disponibiliza, temática discutida no tópico a seguir.

\section{Os Ambientes Virtuais de Ensino e Aprendizagem}

A incorporação de novas tecnologias computacionais de comunicação possibilitou o desenvolvimento de sistemas digitais que integram conjuntos de programas e funcionalidades em uma sofisticada arquitetura computacional que possibilitou que plataformas educacionais hospedem e gerenciem o processo de ensino e aprendizagem realizado virtualmente (FILATRO, 2008).

Tais sistemas ou plataformas, capazes de gerenciar a aprendizagem e também aspectos administrativos e tecnológicos a ela relacionados, são denominados Ambientes Virtuais de Ensino e Aprendizagem

\section{Realização: "') UNIVERSIDADE FEDERAL


$16^{\circ}$ Ergodesign - Congresso Internacional de Ergonomia e Usabilidade de Interfaces Humano Tecnológica: Produto, Informações Ambientes Construídos e Transporte

$16^{\circ}$ USIHC - Congresso Internacional de Ergonomia e Usabilidade de Interfaces Humano Computador

CINAHPA | 2017 - Congresso Internacional de Ambientes Hipermídia para Aprendizagem.
(AVEAs) ou somente Ambientes Virtuais de Aprendizagem (AVAs). A nomenclatura reflete o conceito de "sala de aula online", em que "a ideia de sistema eletrônico está presente, mas é extrapolada pelo entendimento de que a educação não se faz sem ação e interação entre as pessoas" (FILATRO, 2008, p. 120).

De forma semelhante às salas de aula presenciais, os ambientes virtuais de ensino e aprendizagem funcionam como o local onde se realizam as ações educacionais. Eles permitem a publicação, o armazenamento e a distribuição de materiais didáticos, assim como a comunicação entre alunos e equipe de suporte (FILATRO, 2008).

Os AVEAs podem ser utilizados em qualquer âmbito educacional, seja a distância ou em atividades presenciais, possibilitando aumentar as interações para além da sala de aula; encontros presenciais e atividades a distância ou mesmo oferecendo suporte para a comunicação e troca de informações e interação entre os participantes (RIBEIRO et al., 2007).

A importância destes ambientes como ferramenta para trocas de informações, comunicação, interação, disponibilização de material de estudo e como apoio na educação a distância (RIBEIRO, 2007) é tão relevante que os AVEAs são, reconhecidamente, a ferramenta mais utilizada na EaD entre os recursos educacionais disponíveis tanto para o compartilhamento de conteúdos quanto para a comunicação com os estudantes (ABED, 2015).

O AVEA Moodle, padronizadamente, já vem com um conjunto de funções pré-configuradas, apresentando funções de Administrador, Criador de Cursos, Professor (editor), Moderador (não editor), Aluno e Visitante. O usuário é registrado para cada uma dessas funções, conforme seu perfil. $\mathrm{O}$ acesso é dado com um conjunto de permissões préconfiguradas, mas que podem ser editadas e modificadas para melhor atender as particularidades de cada projeto ou do curso que está sendo promovido.

Neste artigo objetiva-se apresentar o resultado de uma prática que envolve uma avaliação feita por estudantes sobre as fragilidades do ambiente. Para isto se faz necessário conhecer um pouquinho das ferramentas disponibilizadas pelo sistema e utilizadas pelos estudantes.

No ambiente Moodle as ferramentas são organizadas em dois grupos que são "atividades" e "recursos". As ferramentas de atividades são normalmente utilizadas para comunicação entre equipe docente e estudantes, processos avaliativos e processos de construção colaborativa de conteúdos. Entre elas podemos enumerar: chat, fórum, questionário, wiki e tarefa. Já as ferramentas de recursos são constantemente usadas para instrução, orientações e para o acesso ao conteúdo a ser estudado e aprendido. Estão, entre elas, as ferramentas: arquivo, livro, página, URL, rótulo entre outras.

Com apresentação das ferramentas mais utilizadas no Moodle, encerra-se a fundamentação sobre os assuntos que amparam o estudo do caso desenvolvido. A seguir apresenta-se a metodologia, os resultados e a conclusão sobre o estudo de caso realizado.

\section{Metodologia}

A avaliação realizada adota uma abordagem metodológica do tipo qualitativa e exploratória. Qualitativa porque não se centra na análise numérica dos dados recolhidos (algo típico das pesquisas quantitativas), mas busca compreender e analisar as características apresentadas pelo objeto de estudo e interpretar os dados recolhidos (TRIVIÑOS, 1994; RICHARDSON, 1999). Além disso, é um estudo exploratório porque, como o próprio nome sugere, propõe-se a explorar, desenvolver e aumentar o conhecimento existente sobre um determinado tema (GIL, 2007; GIL, 2008). Em relação às técnicas utilizadas para a coleta de dados, classifica-se a análise como bibliográfica seguida de um estudo de campo (GIL, 2008). Bibliográfico porque se adotou o conhecimento disponível em publicações acadêmicas de diversos tipos para subsidiar a fundamentação teórica que fundamenta a avaliação. Trata-se também de um estudo de
Realização:

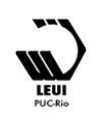


$16^{\circ}$ Ergodesign - Congresso Internacional de Ergonomia e Usabilidade de Interfaces Humano Tecnológica: Produto, Informações Ambientes Construídos e Transporte

$16^{\circ}$ USIHC - Congresso Internacional de Ergonomia e Usabilidade de Interfaces Humano Computador

CINAHPA | 2017 - Congresso Internacional de Ambientes Hipermídia para Aprendizagem. campo, porque buscou levantar dados diretamente com o universo dos sujeitos envolvidos, neste caso, com usuários do AVEA Moodle, ou seja, estudantes de um curso a distância que utilizam o Moodle como ambiente virtual de apoio a mediação pedagógica. Segundo Gil (2007) essa é uma característica essencial desse tipo de estudo: buscar, em um contexto real e aplicado, informações que levem ao aprofundamento dos aspectos estudados.

A citada pesquisa de campo fez uso do questionário como instrumento para a realização da coleta de dados. Considerando que este procedimento é definido como "uma série ordenada de questões que são submetidas a pessoas com o propósito de obter informações, que devem ser respondidas por escrito e sem a presença do entrevistador" (GIL, 2007; GIL, 2008; RICHARSON, 1999; MARCONI, LAKATOS, 2010), o questionário foi aplicado na forma de uma questão, dividida em três subitens.

A questão foi inserida na prova presencial da componente curricular de "Tecnologias

Educacionais" do curso de Pós-graduação Lato Sensu, em nível de Especialização, em Formação Pedagógica para Docência na Educação Profissional e Tecnológica do Instituto Federal de Santa Catarina (IFSC), ofertada pelo Centro de Referência em Formação e Educação a Distância (CERFEAD) em parceria com outras instituições da Rede Federal de Educação Profissional Científica e Tecnológica (RFEPCT), vinculados à Rede E-Tec, curso do qual os autores deste artigos são docentes.

Considerando o espectro dos participantes, a amostra foi do tipo "não probabilística por conveniência". Este tipo de amostragem caracteriza-se pela escolha dos participante por meio de critérios pré-determinados, sem o uso de um instrumental estatístico, sendo o elemento pesquisado selecionado por estar acessível e disponível no local e momento em que a pesquisa se realiza.

Com duração prevista para 18 meses e carga horária para 560 horas, o curso do qual a amostra faz parte tem por objetivo habilitar profissionais para atuar na Educação Profissional e Tecnológica (EPT), nas esferas da docência, da intervenção técnico-pedagógica, no desenvolvimento de projetos de extensão tecnológica e pesquisa aplicada e na gestão institucional, com vistas à compreensão, ao planejamento e à implementação de novos processos na EPT.

O curso teve início em 10 de dezembro de 2015 e o questionário foi aplicado na data de 13 de outubro e 03 de novembro de 2016 com os cursistas matriculados na citada componente curricular. Destaca-se que a prova presencial aconteceu aproximadamente 11 meses depois do início do curso, o que significa que os respondentes já possuíam, neste momento, experiência com a plataforma Moodle de modo a poder dar opiniões consistentes sobre a mesma.

Além disso, a componente curricular de "Tecnologias Educacionais" tem, prevista em sua ementa, o estudo de ambientes virtuais, da aprendizagem colaborativa apoiada por computador e de comunidades virtuais de aprendizagem.

O curso conta com 110 alunos inscritos, dos quais 67 realizaram a avaliação presencial e responderam às questões propostas. Sendo um curso $\mathrm{EaD}$, cursistas de diferentes locais do estado de Santa Catarina participaram como respondentes. Como, para esta oferta, foi firmada uma parceria com o Instituto Federal Fluminense (IFF do Rio de Janeiro), também houve participantes deste local. A Tabela 1 apresenta o número de respondentes de cada local.

Realização:




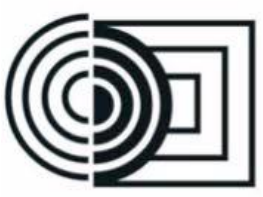

$16^{\circ}$ Ergodesign - Congresso Internacional de Ergonomia e Usabilidade de Interfaces Humano Tecnológica: Produto, Informações Ambientes Construídos e Transporte

$16^{\circ}$ USIHC - Congresso Internacional de Ergonomia e Usabilidade de Interfaces Humano Computador

CINAHPA | 2017 - Congresso Internacional de Ambientes Hipermídia para Aprendizagem.

\begin{tabular}{|c|c|}
\hline N. de respondentes & $\begin{array}{c}\text { Local (Cidade - Estado - } \\
\text { Instituição) }\end{array}$ \\
\hline 12 & Rio de Janeiro - RJ - IFF \\
\hline 11 & Florianópolis - SC - IFSC \\
\hline 12 & Tubarão - SC - IFSC \\
\hline 17 & Xanxerê - SC - IFSC \\
\hline 15 & Itajaí- SC - IFSC \\
\hline & Total : 67 respondentes \\
\hline
\end{tabular}

Tabela 1: Número de respondentes por local Fonte: Elaboração dos autores (2017).

Considerando a Tabela 1, o percentual de respostas obtidas em relação a amostra total foi de mais de $50 \%$, índice maior que os $25 \%$ previsto e descrito por Gillham (2000), Gil (2008), Marconi e Lakatos (2010), Santos (2010) e Gray (2012), como o mínimo necessário para considerar a amostra respondente relevante.

As questões propostas para os cursistas tinham o seguinte enunciado orientador e foram apresentadas na forma de um quadro no qual cada respondente poderia descrever a sua opinião sobre o aspecto descrito (Quadro 1). Eram, portanto, questões abertas na qual o estudante-usuário estava livre para expressar qualquer opinião.

Enunciado: Um Ambiente Virtual de Ensino e Aprendizagem (AVEA), na modalidade de educação a distância, constitui-se como um dos locais de mediação pedagógica entre instituição, equipe docente e estudantes. No IFSC, utiliza-se como

plataforma para esse fim o Moodle. Considerando, que essa plataforma foi apresentada no nosso material didático e estudada em nossa unidade curricular, complete o quadro a seguir, a partir de sua experiência e visão crítica como usuário deste AVEA ao longo deste curso de especialização.

Moodle - Ambiente Virtual de Ensino e Aprendizagem

Fragilidades percebidas como Potencialidades do uso em sua usuário atuação profissional

Proposições para melhoria da organização de cursos e unidades curriculares no ambiente Moodle

Quadro 1: Formato do questionário

Fonte: Elaboração dos autores (2017).
Conforme é possível observar no Quadro 1, o questionário aplicado com os estudantes-usuários da plataforma Moodle buscou recolher dados a respeito de fragilidades, potencialidades e possibilidades de melhoria para/sobre o uso da plataforma como apoio a mediação pedagógica.

Neste estudo, apresentam-se apenas os resultados relacionados às fragilidades percebidas pelos usuários. As potencialidades e proposições de melhoria estão sendo compiladas e serão publicadas em estudos posteriores.

No tópico a seguir, apresentam-se as respostas obtidas em relação às fragilidades e a análise dos resultados do questionário aplicado.

\section{Resultados e discussão}

O questionário foi proposto com questões de respostas abertas, ou seja, não havia respostas sugeridas ou pré-determinadas e, por isso, foram abordados uma grande variedade de tópicos, fato que dificultou a sistematização dos dados. Entretanto, como se trata de uma pesquisa qualitativa, buscou-se encontrar, na análise dos resultados, visões similares e aspectos relevantes para a discussão e reflexão sobre como a plataforma se apresenta para os usuários pesquisados.

Assim sendo, as respostas foram compiladas uma a uma e posteriormente agrupadas nas seguintes temáticas para serem melhor analisadas: fragilidades na utilização, usabilidade, interação, aspectos didáticos pedagógicos, interface e recursos disponíveis e acessibilidade.

Em relação aos aspectos apontados como fragilidades, foram identificadas 56 diferentes particularidades e cada gráfico a seguir descreve cada uma delas de acordo com a sua temática com percentuais que expressam quantas vezes um determinado aspecto foi citado.

\section{Fragilidades na utilização}

Os dois aspectos mais citados nesta temática, conforme é possível visualizar na Figura 1, foram 


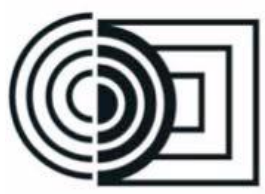

"fragilidade da conexão (quedas e travamentos" e "pouco espaço para upload e armazenamento de arquivos". Ambos os pontos não se relacionam diretamente com a plataforma Moodle, mas com um aspecto importante para o desenvolvimento, aprimoramento e inovação dos modelos de educação a distância online. A fragilidade da conexão, por exemplo, ocasiona quedas e travamentos que impedem a visualização dos conteúdos disponibilizados na forma audiovisual (tais como vídeos da internet, videoaulas e webconferências gravadas). O pouco espaço para upload e armazenamento de arquivos dificulta o uso de recursos didáticos como estes citados e outros mais complexos tais como animações interativas, por exemplo, que também exigem conexões mais estáveis.

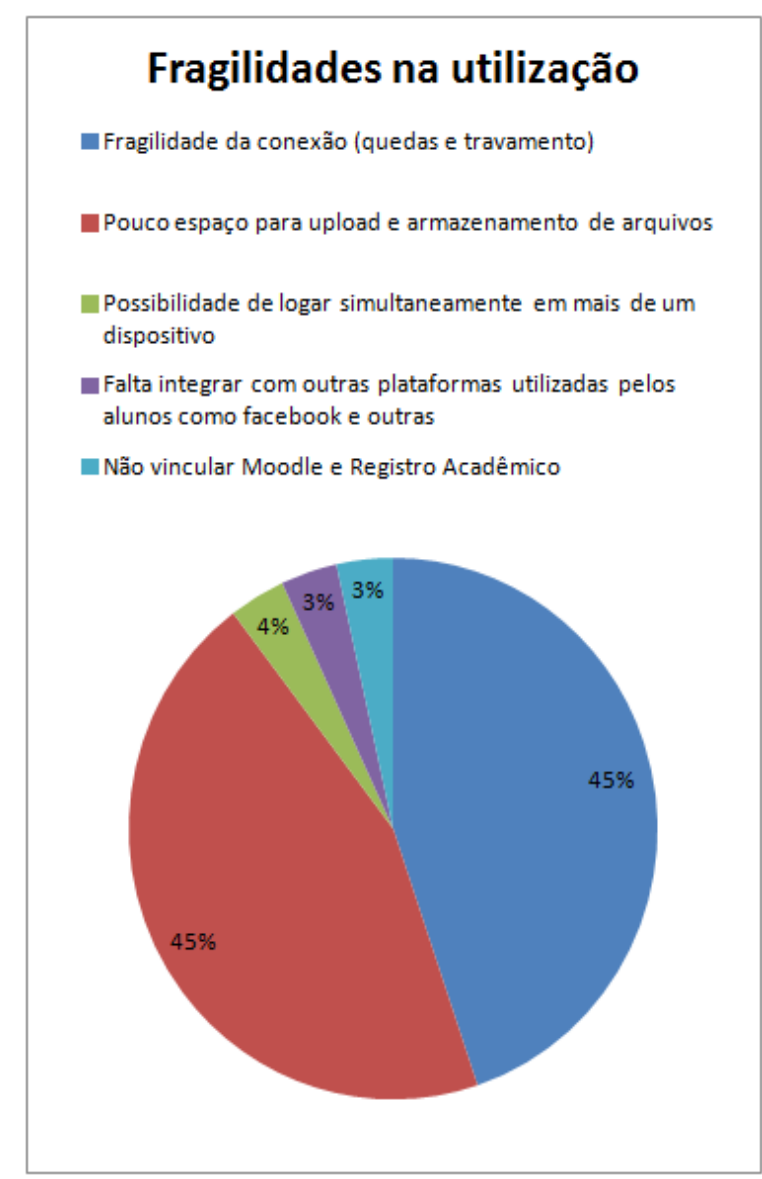

Figura 1: Fragilidades na utilização Fonte: Elaboração dos autores (2017).

As demais citações referiram-se à possibilidade de integração com outras plataformas, tais como as $16^{\circ}$ Ergodesign - Congresso Internacional de Ergonomia e Usabilidade de Interfaces Humano Tecnológica: Produto, Informações Ambientes Construídos e Transporte

$16^{\circ}$ USIHC - Congresso Internacional de Ergonomia e Usabilidade de Interfaces Humano Computador

CINAHPA | 2017 - Congresso Internacional de Ambientes Hipermídia para Aprendizagem.

redes sociais ou mesmo o registro acadêmico institucional. Em uma época de convergência e sincronicidade da maioria dos dispositivos e aplicativos, certamente este é um ponto de relevância para melhorias futuras.

\section{Usabilidade}

A usabilidade é um termo que expressa a facilidade de um usuário ao utilizar um software ou uma plataforma a fim de realizar uma tarefa. Diversos aspectos estão relacionados a uma boa usabilidade. Entretanto, neste caso, o objetivo era destacar, em especial, as fragilidades da ferramenta e por isso os aspectos apresentado na Figura 2destacam alguns pontos específicos que caracterizam fragilidades na usabilidade do Moodle.

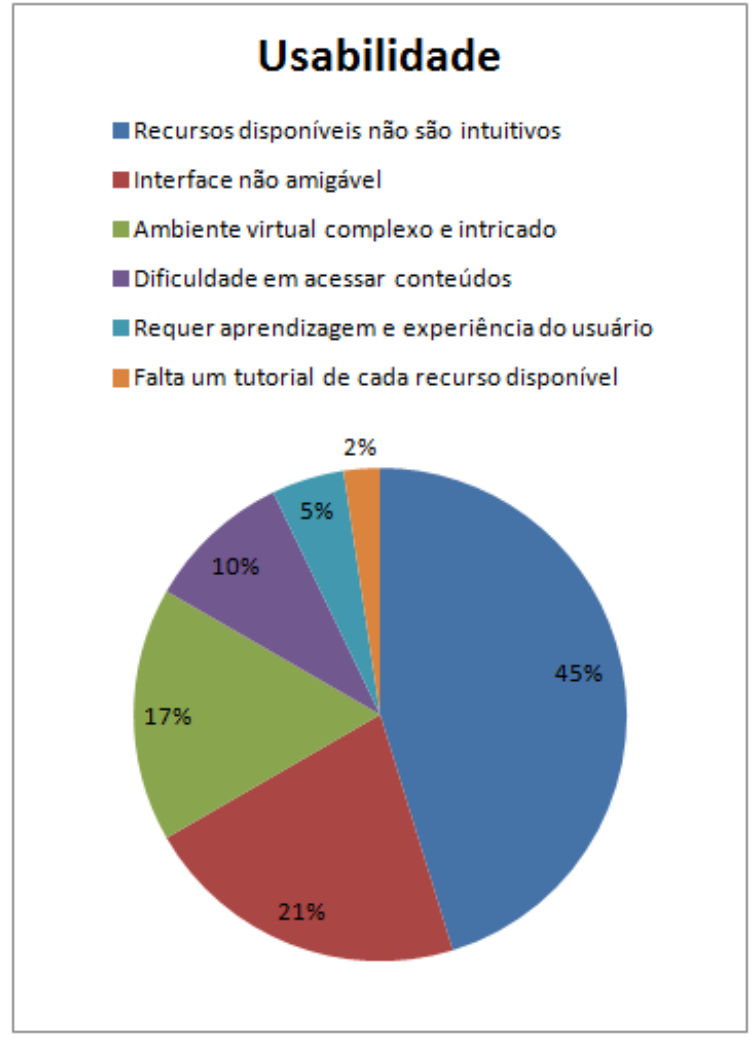

Figura 2: Usabilidade

Fonte: Elaboração dos autores (2017).

Conforme é possível verificar na Figura 2, a maior parte dos usuários declararam que os recursos disponíveis não são intuitivos e que a interação não é amigável. Logo em seguida, um grupo menor de usuários declararam que o ambiente é complexo e 


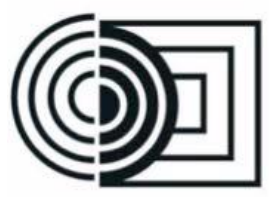

que há dificuldade em acessar seus conteúdos.

Aspectos que consequentemente geram a necessidade de aprendizagem para um uso eficiente da plataforma, aspectos que, em menor número, também foram citados.

\section{Interação}

Outro aspecto relevante em relação a plataforma, refere-se a interação. É por meio da interação professor/estudante e estudante/material didático que a maior parte da mediação pedagógica acontece. A Figura 3 apresenta as principais fragilidades apontadas pelos usuários em relação a esta questão. Ao observá-lo percebe-se que o principal problema é na comunicação entre professor-aluno e aluno-aluno, o que acaba tendo como consequência um aumento da comunicação por outros canais de comunicação, tais como o email.

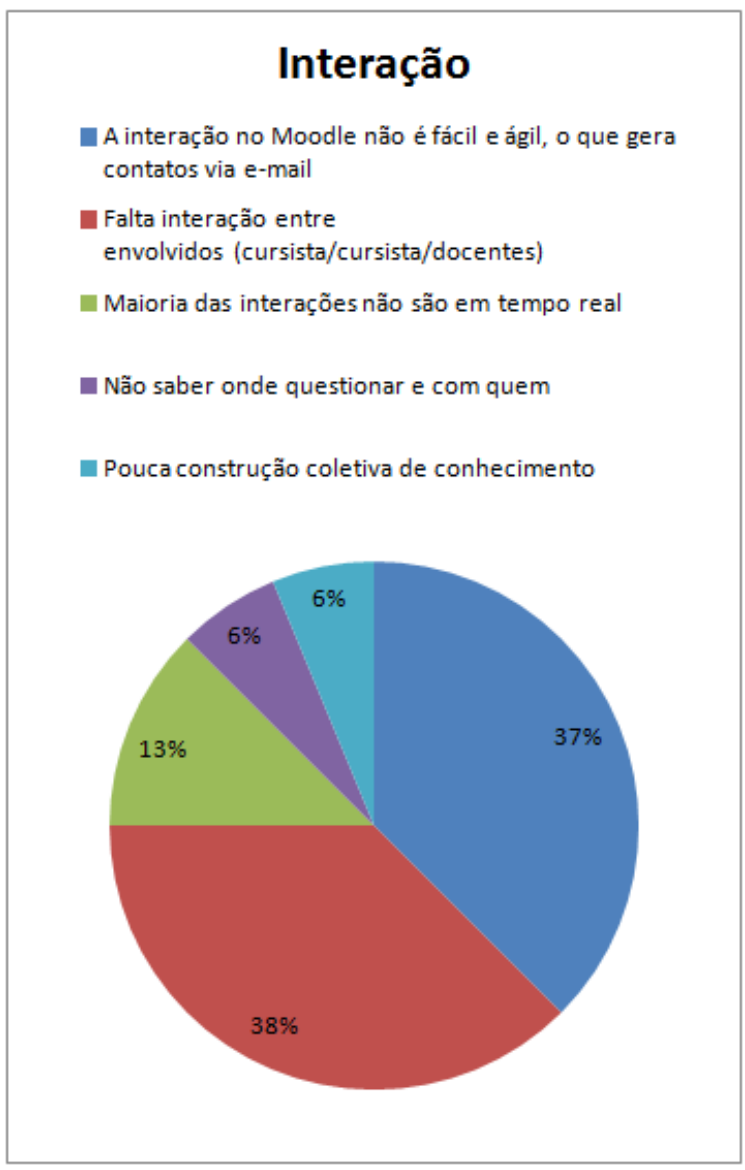

Figura 3: Interação

Fonte: Elaboração dos autores (2017). $16^{\circ}$ Ergodesign - Congresso Internacional de Ergonomia e Usabilidade de Interfaces Humano Tecnológica: Produto, Informações Ambientes Construídos e Transporte

$16^{\circ}$ USIHC - Congresso Internacional de Ergonomia e Usabilidade de Interfaces Humano Computador

CINAHPA | 2017 - Congresso Internacional de Ambientes Hipermídia para Aprendizagem.

\section{Aspectos didático-pedagógicos}

No grupo de respostas intitulado como "aspectos didático-pedagógicos" foram compilados aspectos relacionados especificamente ao acompanhamento dos cursistas oferecido e à sequência didática estabelecida pelos docentes ao longo do curso (tais como materiais de leitura sugeridos e atividades de avaliação propostas).

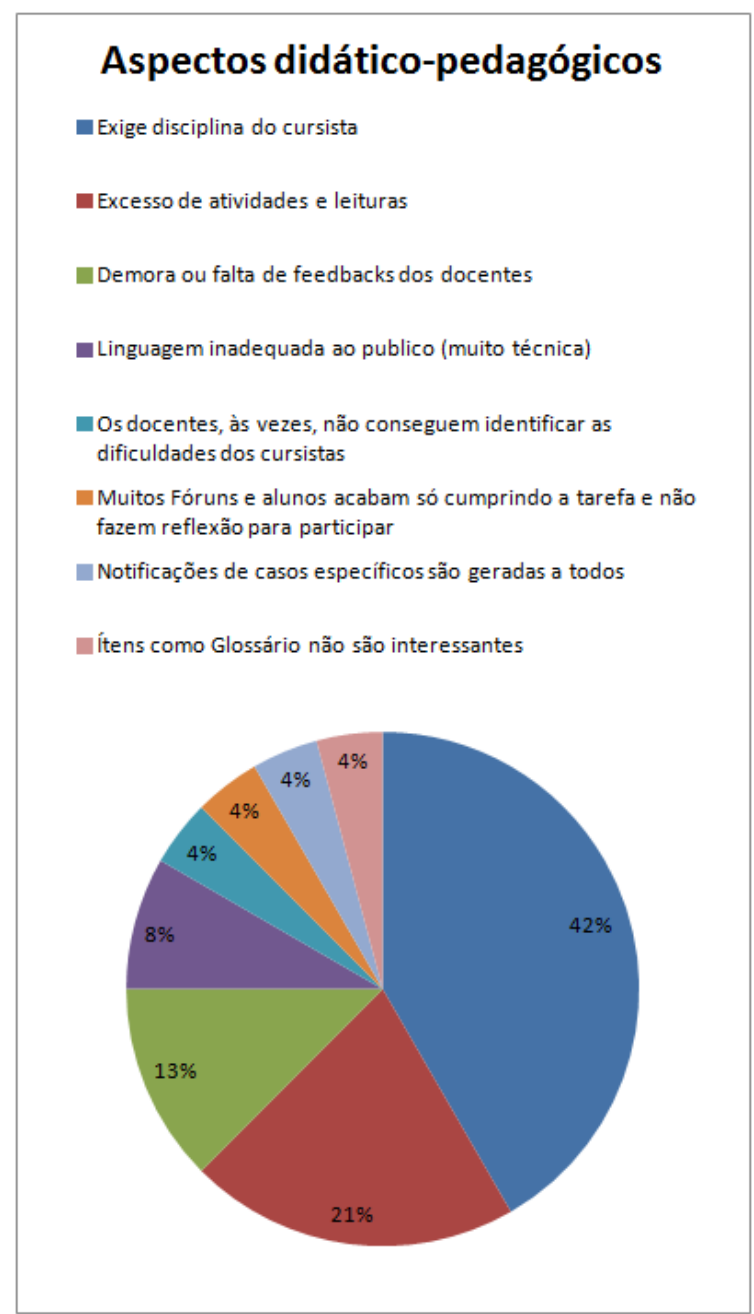

Figura 4: Aspectos didático-pedagógicos Fonte: Elaboração dos autores (2017).

Na Figura 4 é possível observar que, ao utilizar o Moodle como suporte de apoio a aprendizagem, os cursistas observaram a necessidade de muita disciplina para o cumprimento das componentes curriculares, embora também tenham destacado que há excesso de atividades, de leitura e que os professores pecam ao dar feedback. 
$16^{\circ}$ Ergodesign - Congresso Internacional de Ergonomia e Usabilidade de Interfaces Humano Tecnológica: Produto, Informações Ambientes Construídos e Transporte

$16^{\circ}$ USIHC - Congresso Internacional de Ergonomia e Usabilidade de Interfaces Humano Computador

CINAHPA | 2017 - Congresso Internacional de Ambientes Hipermídia para Aprendizagem.

\section{Interface e recursos disponíveis}

Uma interface, como o próprio nome sugere, é um elemento que proporciona uma ligação física ou lógica entre dois sistemas ou partes de um sistema que não poderiam ser conectados diretamente. Já os recursos disponíveis são os materiais didáticos que a plataforma possibilita explorar e que os docentes podem disponibilizar. Neste item também foram compiladas informações referentes à organização das salas virtuais.

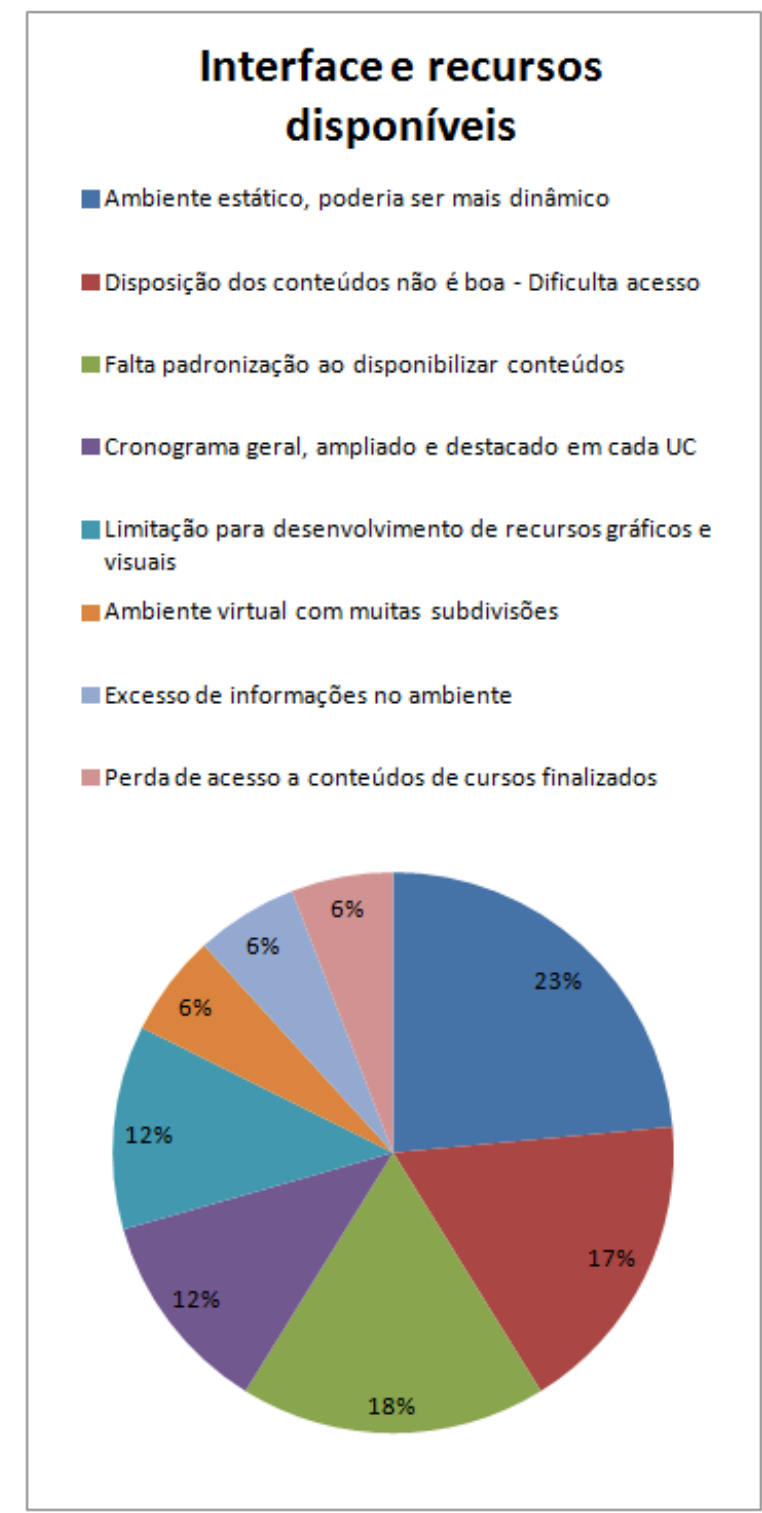

Figura 5: Interface e recursos disponíveis Fonte: Elaboração dos autores (2017).
Em relação a esses aspectos, conforme apresentado na Figura5, a maior parte dos cursistas declara que o Moodle proporciona ambientes estáticos e que as salas virtuais poderiam ser mais dinâmicas e também melhor organizadas - cita-se que a disposição dos conteúdos não facilita o acesso e que o ambiente atual possui muitas subdivisões. Também foi citado que falta padronização dos docentes ao disponibilizar os recursos.

\section{Acessibilidade}

Em relação a acessibilidade, houve apenas duas citações amplas e gerais sobre o tema que não especificam nenhum problema em particular, embora mereçam todo o cuidado e atenção ao realizar um AVEA.

Uma das afirmações referiu-se a "limitação de usabilidade para pessoas com algum tipo de deficiência (visual e/ou auditiva)" e a outra a "alunos com necessidades especiais não são contemplados".

\section{Resultados e discussão}

O estudo apresentado neste artigo faz parte de um projeto de pesquisa ainda não concluído, ou seja, que segue em andamento uma vez que também foram pesquisadas, além das fragilidades, as potencialidades e proposições de melhoria para a plataforma Moodle como um como ambiente virtual de mediação pedagógica. Sabe-se que a compilação e a análise de todos estes aspectos em conjunto, certamente, trarão resultados mais consistentes.

Entretanto, no que tange às fragilidades já foi possível diagnosticar aspectos relevantes que podem contribuir com as pesquisas e aplicações do Moodle em cursos a distância. Observou-se que uma das principais questões refere-se a dinamicidade e flexibilidade do ambiente observadas tanto quando os cursistas referiram-se a upload de arquivos (ainda considerado com pouco espaço disponível) quanto em relação aos recursos e conteúdos disponibilizados. A usabilidade da 
$16^{\circ}$ Ergodesign - Congresso Internacional de Ergonomia e Usabilidade de Interfaces Humano Tecnológica: Produto, Informações Ambientes Construídos e Transporte

$16^{\circ}$ USIHC - Congresso Internacional de Ergonomia e Usabilidade de Interfaces Humano Computador

CINAHPA | 2017 - Congresso Internacional de Ambientes Hipermídia para Aprendizagem.

0Informa\%C3\%A7\%C3\%A3o\%20-

$\% 20$ Henriette.pdf. Acesso em 09 jan. 2017.

plataforma também foi apontada como uma fragilidade, em especial no que se refere a facilidade de acesso aos recursos e a compreensão de como funcionam. O mesmo observa-se com a interação, diagnosticada por alguns como difícil e pouco ágil.

Destaca-se também que muitos aspectos apontados referem-se não somente a plataforma em si, mas a aplicação feita pelos docentes e demais agentes envolvidos no desenvolvimento de um curso a distância. Isso foi destacado de modo especial no que se refere ao feedback aos estudantes e às questões de organização e disponibilização de conteúdos. Tal fato, permite concluir muito bem esta discussão: afinal, as particularidades que cada dispositivo disponibiliza são importantes, mas a sua utilização e a proposta pedagógica adotada serão sempre fundamentais e determinantes em qualquer processo de ensino e aprendizagem.

\section{BIBLIOGRAFIA}

ABED - Associação Brasileira de Educação a Distância. Censo EAD.BR: Relatório Analítico da Aprendizagem a Distância no Brasil 2014. Curitiba: Ibpex, 2015.

FILATRO, Andrea. Design Instrucional na Prática. São Paulo: Pearson Education do Brasil, 2008.

GIL, A. C. Como elaborar projetos de pesquisa. São Paulo: Atlas, 2007.

GIL, A. C. Métodos e técnicas de pesquisa social. São Paulo: Atlas, 2008.

\section{GILLHAM, B. Developing a questionnaire.}

London: Continuum, 2000.

GOMES, Henriette Ferreira. A mediação da informação,comunicação e educação na construção do conhecimento. DataGramaZero - Revista de Ciência da Informação - v.9 n.1 fev/08 ARTIGO 01. Disponível no endereço:

https://repositorio.ufba.br/ri/bitstream/ri/3041/1/Da taGramaZero\%20-

$\% 20$ Revista\%20de\%20Ci\%C3\%Aancia\%20da\%2
GRAY, D. Pesquisa no mundo real. Porto

Alegre: Penso, 2012.

KENSKI, Vani Moreira. Educação e comunicação: interconexões e convergências. Educ. Soc. vol.29 no.104 Campinas Oct. 2008.

Disponível no endereço:

http://www.scielo.br/scielo.php?script=sci_arttext $\& \mathrm{pid}=\mathrm{S} 0101-73302008000300002$. Acesso em 09 jan. 2017.

MARCELO, Rodiney. As TIC's no contexto da ead: limites e possibilidades. Site brasil escola, 2017. Disponível em:

<http://moodle.ead.ifsc.edu.br/mod/book/edit.php? cmid $=34443 \& \mathrm{id}=3873>$. Acesso em: 25 jant. 2016.

MARCON, Karina; GOEDERT, Lidiane. Apropriação tecnológica da formação inicial de professores - uma experiência no curso de Pedagogia Cead |Udesc.

In PráticasPedagógicas na educação a distância - reflexões, experiências e processos. Editora UDESC, Florianópolis, SC. 2015.

MARCONI, M. A.; LAKATOS, E. M. Técnicas de pesquisa: planejamento e execução de pesquisas, amostragens e técnicas de pesquisa, elaboração, análise e interpretação dos dados. São Paulo: Atlas, 2010.

PORTAL EDUCAÇÃO. Utilização do Moodle. 2013.Disponpivel no endereço: http://www.abed.org.br/hotsite/20ciaed/pt/anais/pdf/192.pdf. Acesso em 13/mar 2016.

RIBEIRO, Elvia Nunes; MENDONÇA Gilda A de A.; MENDONÇA, Alzino Furtado. A importância dos ambientes virtuais de aprendizagem na busca de novos domínios da EAD. In: Congresso da Associação Brasileira de Educação a Distância, Goiás. Anais... 2007. Disponível em:

<http://www. abed. org. br/congresso2007/tc/4162007104526am. Pdf >. Acesso em: 23 mar. 2016. 


\section{$16^{\circ}$ \\ ERGODESIGN USIHC CINAHPA}

$16^{\circ}$ Ergodesign - Congresso Internacional de Ergonomia e Usabilidade de Interfaces Humano Tecnológica: Produto, Informações Ambientes Construídos e Transporte

$16^{\circ}$ USIHC - Congresso Internacional de Ergonomia e Usabilidade de Interfaces Humano Computador

CINAHPA | 2017 - Congresso Internacional de Ambientes Hipermídia para Aprendizagem.

RICHARDSON, R. J. et al. Pesquisa Social: métodos e técnicas. São Paulo: Atlas, 1999.

SANTOS, I. E. Manual de métodos e técnicas de pesquisa científica. 7. ed., rev. e atual. Niterói, RJ: Impetus, 2010.

SILVEIRA, Cláudia Alexandra Bolela. Mediação pedagógica e educação a distância: as competências do tutor e a motivação para aprendizagem. ESUD - XI Congresso de educação superior a distância - UNIREDE.

Florianópolis, ago. 2014. Disponível no endereço http://esud2014.nute.ufsc.br/anaisesud2014/files/pdf/128129.pdf. Acesso em 10 jan. 2017.

TRIVINOS, A. N. S. Introdução a pesquisa em ciências sociais: a pesquisa qualitativa em educação. São Paulo (SP): Atlas, 1994. 